\title{
Multiservice single-stage surgery for intracardiac leiomyomatosis
}

\author{
Juan A Siordia * Todd R Golden, Sreekumar Subramanian \\ Department of Surgery, University of Arizona Medical Center, University of Arizona, Ave, Tucson, AZ, United States
}

Received: February 2, 2016

Accepted: March 6, 2016

Online Published: March 24, 2016

DOI: $10.5430 /$ css.v2n2p49

URL: http://dx.doi.org/10.5430/css.v2n2p49

\begin{abstract}
Intracardiac leiomyomatosis is a rare case that is often confused with more common diseases typically right atrial myxoma. It involves tumor extension of the uterine wall tumor through the inferior vena cava (IVC) and into the right atrium. Since its discovery in 1907, very few cases have been reported. The disease is treated surgically using one of two surgical approaches: the two-stage and the single-stage approach. The following case report involves an unusual presentation of a Caucasian woman with intracardiac leiomyomatosis who underwent a successful single-stage approach with coordinated involvement from Gynecological-Oncological, Urological, Vascular, and Cardiothoracic Surgery services.
\end{abstract}

Key Words: Leiomyomatosis, Intracardiac, Single-stage operation

\section{INTRODUCTION}

Intravascular leiomyomatosis, is a rare condition where a leiomyoma tumor extends through the uterus and into the venous circulation. Less than $10 \%$ of cases of intravenous leiomyomatosis exhibit cardiac extension (intracardiac leiomyomatosis). ${ }^{[1]}$ The tumor can extend from a leiomyoma through the right internal iliac vein and into the right atrium. ${ }^{[2]}$ Tumor extending beyond the tricuspid valve and obstructing the right ventricular outflow tract has the potential to cause right heart failure and death. ${ }^{[3]}$ The most common presentation includes dyspnea, syncope, and lower extremity edema. However, it may also be found incidentally in an asymptomatic patient. ${ }^{[4,5]}$

Intracardiac leiomyomatosis requires surgical intervention, with the first successful operative resection reported in 1980; all previous cases were fatal. ${ }^{[6]}$ This condition can be treated via two-stage procedure with a sternotomy first for intracar- diac tumor removal followed by a laparotomy for complete tumor excision, or via a single-stage operation with a sternotomy and laparotomy approach under cardiopulmonary bypass. ${ }^{[2-5]}$ The following case report employed a single-staged surgery with the involvement of Cardiothoracic, GynecologyOncology, Urological, and Vascular Surgery services.

\section{CASE PRESEntation}

A 33-year-old nulliparous Caucasian woman with a past medical history significant for two myomectomies ( 1 and 7 years prior) for leiomyomas presented with a 6 month history of intermittent headache, abdominal distention, back pain, and occasional nausea and vomiting. She also noted gradual onset of leg swelling and 20-pound weight gain as well as symptoms of incomplete urinary bladder emptying.

On initial screening, she was found to have malignant hypertension, which was controlled with nicardipine. Mag-

\footnotetext{
* Correspondence: Juan A Siordia; Email: jas @email.arizona.edu; Address: Department of Surgery, University of Arizona Medical Center, University of Arizona, 1501 N, Campbell, Ave, Tucson, AZ, 85719, United States.
} 
netic resonance imagining (MRI) showed a large pelvic mass $(16 \mathrm{~cm} \times 13.2 \mathrm{~cm} \times 22.6 \mathrm{~cm})$ extending into the inferior vena cava (IVC) and into the right atrium, nearly filling the right atrium $(5.5 \mathrm{~cm} \times 4.0 \mathrm{~cm} \times 3.5 \mathrm{~cm})$ (see Figures 1 and 2 ). Interventional radiology performed a biopsy through the jugular vein, which revealed pathology consistent with benign adrenal tissue. Suggesting a normal biopsy of the adrenal glands, another biopsy was preformed with pathology suggestive of benign smooth muscle.

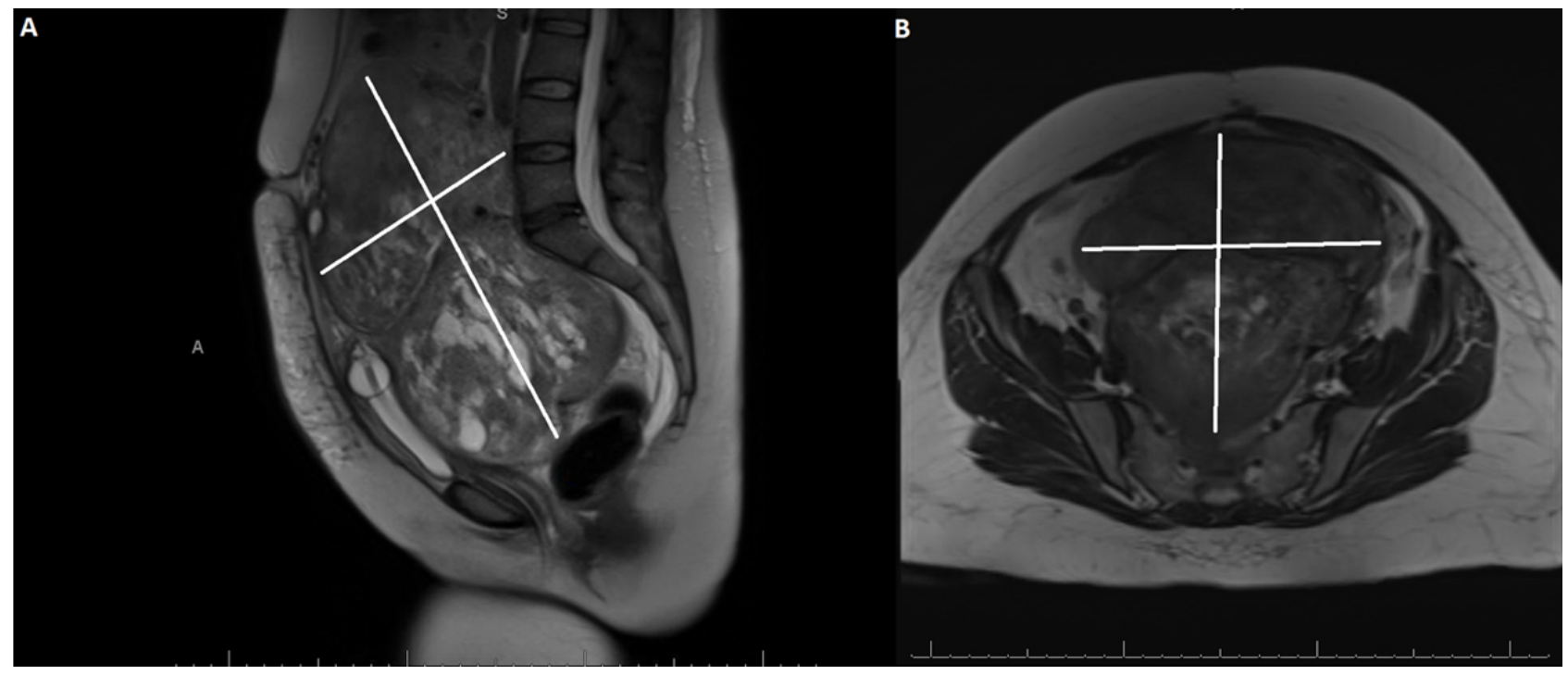

Figure 1. Intrauterine leiomyomatosis measuring $16 \mathrm{~cm} \times 13.2 \mathrm{~cm} \times 22.6 \mathrm{~cm}$ The tumor extends from the base of the uterus to the lower abdominal region around L3-LA region (A). It also expands wide within the pelvic-abdominal region $(B)$. The white lines represent the measurements.

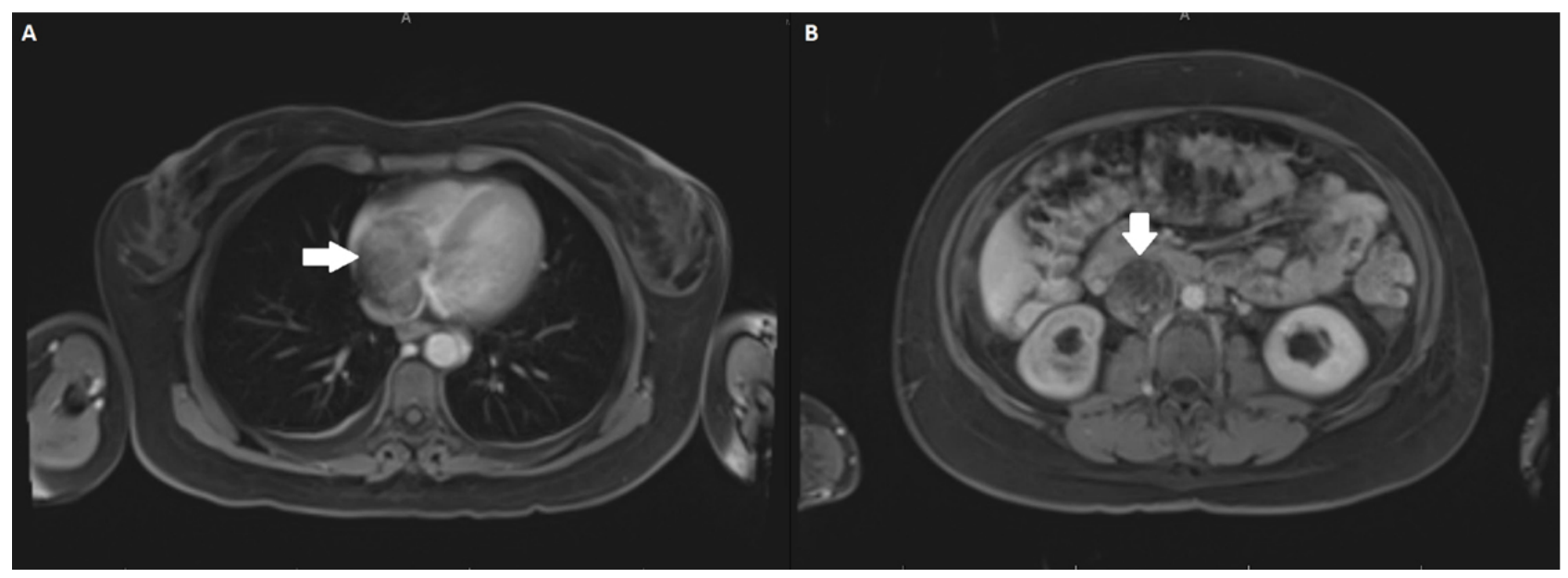

Figure 2. Leiomyomatosis reaching the right atrium

(A) through the inferior vena cava; (B) The tumor expands from the uterus, through the inferior vena cava, and into the right atrium. The white arrows direct toward the presence of the $5.5 \mathrm{~cm} \times 4.0 \mathrm{~cm} \times 3.5 \mathrm{~cm}$ tumor almost completely filling the right atrium.

Surgical excision was then undertaken by a combined surgi- Figure 3). Urology began the operation by performing a cyscal team involving Gynecological-Oncological, Urological, Vascular, and Cardiothoracic Surgery services. At surgery trans-esophageal echocardiography confirmed evidence of right atrial tumor extension without extension into the right ventricle and preserved function of the tricuspid valve (see toscopy and placing a Foley and bilateral ureteral catheters. The bladder and the urethra were noted to be pushed anteriorly by the tumor mass.

Gynecology-Oncology then performed a midline laparotomy incision. The mass was encountered as coming from the 
lower uterine segment or cervix and extending into the culde-sac over the right peritoneal space. Due to extensive peritoneal attachment, the mass was not mobile. The internal iliac system was embolized and the vascular pedicles were isolated. Both round ligaments were divided to reveal the retroperitoneal space, ureters, and gonadal vessels. The procedure continued as a typical hysterectomy when operating on the left side. The right side had more fibroid involvement, requiring more dissection of peritoneal attachments. Three large uterine fibroids were discovered and resected. The mass was eventually removed from the pelvic area.

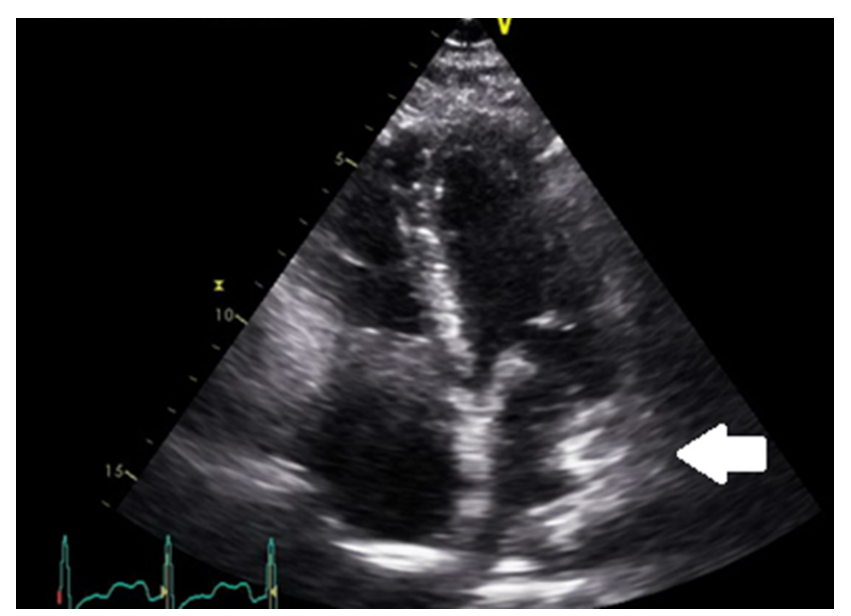

Figure 3. Transesophageal echocardiogram showing the extension of the leiomyomatosis into the right atrium (white arrow)

Note that the tumor does not extend through the tricuspid valve into the right ventricle.

Cardiothoracic and Vascular Surgery then proceeded in removing the remainder of the tumor. A median sternotomy was performed while the IVC was exposed further via manipulation and movement of intra-abdominal organs. The patient was then cannulated via the ascending aorta and superior vena cava (SVC). A femoral venous cannula was then placed into the left femoral vein and advanced into the IVC adjacent to the tumor mass in the infrahepatic IVC. The patient was started on cardiopulmonary bypass and cooled to $28^{\circ} \mathrm{C}$ for hypothermic cardiac arrest. The SVC and IVC were carefully snared. An oblique right atriotomy was then performed. The smooth-walled $5 \mathrm{~cm}$ right atrial mass was exposed by placing four pledgeted Prolene sutures. The right atrial mass was clearly too large to pass through the IVC and was therefore transected with the IVC caval snare. An aortic cross-clamp was placed across the transverse aortic arch distal to the left carotid artery, achieving antegrade bilateral brain perfusion at a flow rate of $10 \mathrm{ml} / \mathrm{kg} / \mathrm{min}$. The left femoral venous cannula was then clamped and a cavotomy was performed in the abdomen. The tumor mass in the Published by Sciedu Press suprahepatic IVC was pushed caudally while the rest was pulled below. Once evacuated, no residual tumor mass or debris was visible within the IVC, and the hepatic vein ostia could be visualized as patent. Tumor mass was sent for a pathology read, which came back consistent with intravascular leiomyomatosis without histological signs of malignancy. Once the cavotomy was clamped, the femoral venous cannula was readvanced into the abdominal IVC, the aortic cross-clamp released, and the patient returned to full flow cardiopulmonary bypass. Once stable on cardiopulmonary bypass, the patient was rewarmed to $36^{\circ} \mathrm{C}$. Cerebral saturations remained at or above baseline during the time period of circulatory arrest and on cardiopulmonary bypass. Once rewarmed, the patient was removed from bypass with excellent biventricular function, a well-functioning tricuspid valve, and patent right atrium and IVC. All operating fields were closed and the patient carefully weaned from anesthesia.

Post-operatively, the patient was extubated and ambulatory one day after surgery. Blood pressure was controlled with metoprolol and lisinopril. An event of shortness of breath following fluid overload, was resolved with a single dose of furosemide. The Foley and ureteral stents were removed on the fifth day and the patient discharged home on the seventh day post surgery.

Follow-up echocardiogram at 14 weeks was essentially normal with no evidence of intracardiac mass. Abdominopelvic MRI 7 weeks post surgery was remarkable for two pelvic masses: one suggestive of residual tumor and the other postsurgical fibrous tissue. A $2.9 \mathrm{~cm} \times 2.5 \mathrm{~cm}$ homogeneously enhancing tubular structure demonstrating heterogeneous $\mathrm{T} 2$ signal in the right lower pelvis along the pelvic sidewall was most consistent with residual disease. Just medial to this and adjacent to the right vaginal cuff, was a $1.9 \mathrm{~cm} \times 1.1 \mathrm{~cm}$ mass that was $\mathrm{T} 2$ hypointense with heterogeneous delayed enhancement, most consistent with post surgical fibrotic tissue. At 14 weeks post surgery, abdominopelvic MRI showed both pelvic masses without significant change. Due to asymptomatic presentation, the surgical teams in consultation with the patient decided on monitoring with serial imaging (see Figures 4 and 5).

\section{DiscuSSION}

Intracardiac leiomyomatosis is a large, benign tumor extending from the uterus to the right heart chambers. The first cases of intracardiac leiomyomatosis were described by Durck and Hormann in 1907 in German, yet the first report in English did not appear until 1974. ${ }^{[7-9]}$ The tumor travels from the uterine wall into the IVC via extension through the iliac vein $(66.2 \%)$, ovarian vein $(17.6 \%)$, or renal vein $(14.2 \%){ }^{[4]}$ With surgical treatment, survival is extremely 
high with reports suggesting more than 12 years without complications. ${ }^{[10]}$ Recurrence from complete resection has never been documented while incomplete resections have a $33 \%$ recurrence rate. ${ }^{[4]}$

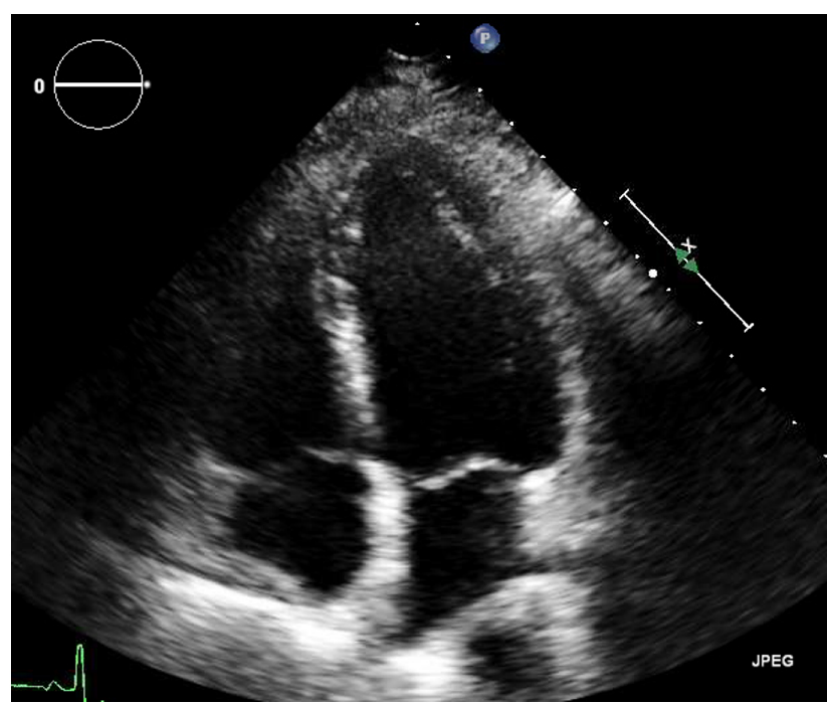

Figure 4. Echocardiogram 14 weeks post surgery showing an essentially normal presentation
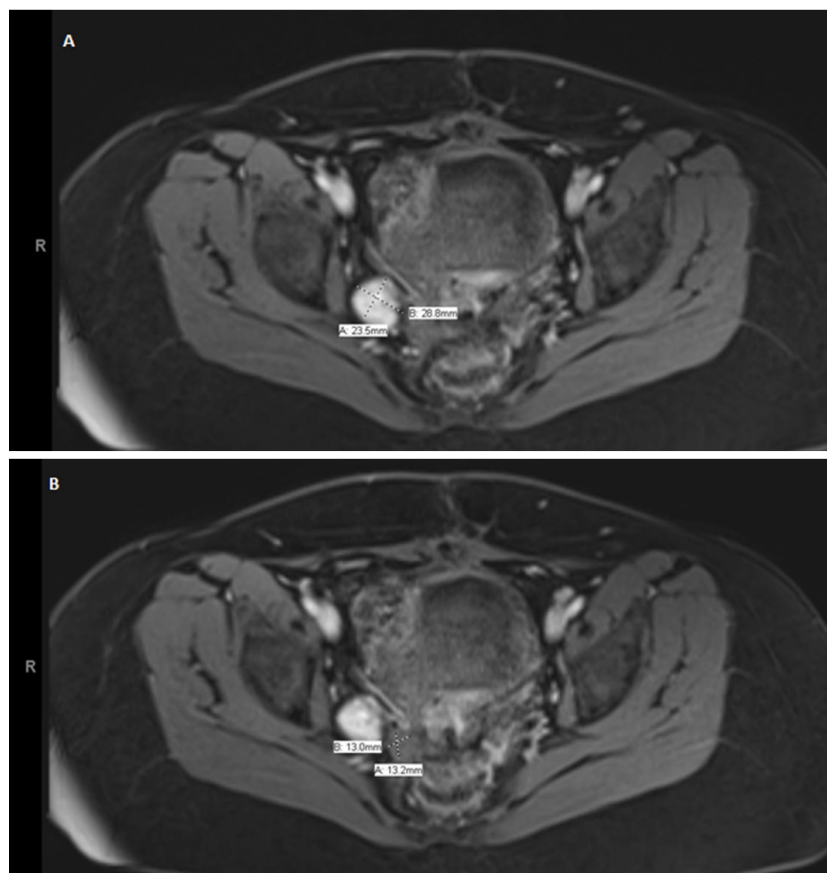

Figure 5. MRI of the pelvis 14 weeks post surgery

(A) two masses suggestive of residual tumor, and (B) post-surgical fibrous tissue, measuring $2.3 \mathrm{~cm} \times 2.9 \mathrm{~cm}$ and $1.3 \mathrm{~cm} \times 1.3 \mathrm{~cm}$ respectively.

Pathology specimens suggest similarities to smooth muscle. Cytogenic and molecular studies suggest a relation with abnormal karyotype 45, XXder(14)t(12;14)(q15;q24), -22. ${ }^{[11]}$
Immunohistochemical staining shows desmin and smooth muscle actin suggestive of smooth muscle composition. ${ }^{[12]}$ During the case, the second biopsy from interventional radiology confounded the surgical services due to suspicion of tunica media tissue. However, the myometrium where this tumor arises is also comprised of smooth muscle. Although histologically benign, the extension of the tumor through the blood network and the possibility of causing right heart failure and cardiac arrest gives it a technical metastatic characteristic. ${ }^{[2,3,5]}$

The presentation of a woman with intravascular leiomyomatosis includes an average age of 47.6 (range 20-81 years) that is multiparous (75\%), has a history of previous hysterectomy or myomectomy (53.6\%), and has a coexisting uterine leiomyoma on admission (29.9\%). Most common presentations include dyspnea (65\%), syncope (47\%), and lower extremity edena (46\%) however, $13 \%$ of patients are asymptomatic at presentation. ${ }^{[4]}$ This case reports a 33-year old woman with history of leiomyomas and myomectomies, but her presentation was unusual in that she was nulliparous and her primary complaint was a 6-month headache.

Upon clinical suspicion, the extent of involvement is usually in the right ventricle (47.1\%), right atrium $(40.1 \%)$, or pulmonary artery $(12.8 \%)$. The rarity of the tumor commonly leads to misdiagnosis as a right atrial myxoma (29.5\%), thrombus-in-transit (3.8\%), or an IVC embolism (1.9\%). ${ }^{[4]}$ An echocardiogram revealing a right-sided cardiac mass originating from the IVC in a woman with a history of hysterectomy or uterine leiomyoma should raise the suspicion of intracardiac leiomyomatosis. Further suspicion is raised if the mass has no stalk and moves freely within the IVC and right atrium since the tumor extends from the IVC and is highly mobile with no stalk or adherence to the right atrial wall. When extension is limited to the right atrium, it moves freely near the tricuspid orifice. Computed tomograms also reveal pelvic masses extending into the right internal and common iliac veins with continuation into the inferior vena cava. $^{[13]}$

Surgery can be performed via a single or two-stage operation. The two-stage procedure involves first performing the sternotomy to remove the intracardiac mass to relieve the patient of symptoms and decrease the risk of heart failure and cardiac arrest. A follow up laparotomy is performed from 1 week to 2 years later, to remove the remaining tumor. ${ }^{[?, 14]}$ There are two main advantages of the two-stage operation over the single-stage approach. First, it is more suitable for patients who cannot withstand the trauma and loss of blood in a one-stage approach. Second, it is recommended when the tumor adheres extensively to the vascular wall. The draw- 
back of the two-stage operation is the risk of reextension into the right heart chambers. ${ }^{[16]}$

The one-stage operation, as employed in this case, involves performing the sternotomy and laparotomy simultaneously. Both stages are performed under cardiopulmonary bypass and typically with hypothermic circulatory arrest,${ }^{[3]}$ similar to the procedure described in this case. However, there have been few cases that report the avoidance of cardiac arrest. ${ }^{[2]}$

\section{REFERENCES}

[1] Jung Choi I, Han MS, Cha MS. A case of huge intravenous leiomyomatosis with intracrdiac extension. J Womens Med. 2010; 3: 29-31. http://dx.doi.org/10.5468/jwm.2010.3.1.29

[2] Yanagiya A, Yamada O, Nanbu T, et al. One-stage resection of intravenous leiomyomatosis extending into the right atrium. Kyobu Geka. 2015; 68: 188-91. PMid: 25743551.

[3] Pesi B, Moraldi L, Antonuzzo L, et al. Single-stage operation using hypothermic circulatory arrest to remove uterine intravenous leiomyomatosis extended to the vena cava and right atrium. Int J Gynaecol Obstet. 2014; 129: 87-8. PMid: 25579748. http: //dx.doi.org/10.1016/j.ijgo.2014.10.021

[4] Li B, Chen X, Chu YD, et al. Intracardiac leiomyomatosis: a comprehensive analysis of 194 cases. Interact Cardiovasc Thorac Surg. 2013; 17: 132-8. PMid: 23563052. http://dx.doi.org/10.10 93/icvts/ivt117

[5] Cruz I, Joao I, Stuart B, et al. Intravenous leiomyomatosis: a rare cause of intracardiac mass. Rev Port Cardiol. 2014; 33: 735. PMid: 25455948. http://dx.doi.org/10.1016/j.repc. 2014 .04 .005

[6] Timmis AD, Smallpeice C, Davies AC, et al. Intracardiac spread of intravenous leiomyomatosis with successful surgical excision. N Engl J Med. 1980; 303: 1043-4. PMid: 7421892. http://dx.doi . org/10.1056/NEJM198010303031806

[7] Durck H. Ueber ein kontinvierlich durch die learned hohlvene in das herz vorwachsendes fibromyoma des uterus. Munchen Med Wochenschr. 1907; 54: 1154.

[8] Hormann K. Uber einen fall von myomatosem uterus tumor. Zentralbl Gynakol. 1907; 51: 1604-5.

[9] Mandelbaum I, Pauletto FJ, Nasser WK. Resection of a leiomyoma of the inferior vena cava that produced tricuspid valvular obstruction. J Thorac Cardiovasc Surg. 1974; 67: 561-7. PMid: 4818531.
Due to the involvement of the cardiac, vascular, reproductive, and urinary systems, multiple surgical team specialties are required in the operating room. Three advantages are noted with the one-stage approach. First, it avoids the possible interval complications of reextension and hemodynamic complications presented with the two-stage approach. Second, it decreases the exposure of general anesthesia to only one event. Finally, it serves an economic benefit due to the single surgery. ${ }^{[17,18]}$
[10] Kuenen BC, Slee PHTJ, Seldenrijk CA, et al. Intravenous leiomyomatosis complicated by Budd-Chiari syndrome. Postgrad Med J. 1996; 72: 686-8. PMid: 8944214. http://dx.doi.org/10.1136 /pgmj . 72.853.686

[11] Quade BJ, Dal Cin P, Neskey DM, et al. Intravenous leiomyomatosis: molecular and cytogenetic analysis of a case. Mod Pathol. 2002; 15: 251-6. PMid: 11904348. http://dx.doi.org/10.1038/modpa thol.3880529

[12] Ricci MA, Cloutier LM, Mount S, et al. Intravenous leiomyomatosis with intracardiac extension. Cardiovasc Surg. 1995; 3: 693-6. http: //dx .doi.org/10.1016/0967-2109(96)82871-7

[13] Li RJ, Shen YG, Sun Y, et al. Intravenous leiomyomatosis with intracardiac extension: echocardiographic study and literature review. Tex Heart I J. 2014; 41: 502-6. PMid: 25425982. http: //dx.doi.org/10.14503/THIJ-13-3533

[14] Liu B, Liu C, Guan H, et al. Intravenous leiomyomatosis with inferior vena cava and heart extension. J Vasc Surg. 2009; 50: 897-902. http://dx.doi.org/10.1016/j.jvs.2009.04.037

[15] Luciani N, Anselmi A, Glieca F, et al. Diagnostic and surgical issues in emergency presentation of a pelvic leiomyoma in the right heart. Ann Thorac Surg. 2009; 87: 1589-92. PMid: 19379915. http://dx.doi.org/10.1016/j.athoracsur.2008.09.077

[16] Altinok D, Yildiz YT, Tacal T, et al. MRI of intravascular leiomyomatosis extending to the heart. Eur Radiol. 2000; 10: 871. PMid: 10823652. http://dx.doi.org/10.1007/s003300051023

[17] Lee S, Kim DK, Narm KS, et al. Pulmonary artery embolizatoin of intravenous leiomyomoatisis extending into the right atrium. Korean J Thorac Cardiovasc Surg. 2011; 44: 243-6. PMid: 22263160. http://dx.doi.org/10.5090/kjtcs.2011.44.3.243

[18] Castelli P, Caronno R, Piffaretti G, et al. Intravenous uterine leiomyomatosis with right heart extension: successful two-stage surgical removal. Ann Vasc Surg. 2006; 20: 405-7. PMid: 16583249. http://dx.doi.org/10.1007/s10016-006-9024-0 